\title{
Suppression of Melanose Caused by Diaporthe citri on Citrus Leaves Pretreated with Bio-sulfur
}

\author{
Yong Ho Shin ${ }^{1}$, Eun Ju Ko ${ }^{1}$, Su Jeong Kim², He Nam Hyun ${ }^{1,3}$, and Yong Chull Jeun (1) 1,3,* \\ ${ }^{I}$ College of Applied Life Science, Major of Plant Resources \& Environment, Jeju National University, Jeju 63243, Korea \\ ${ }^{2}$ Postech Biotech Center, Pohang University of Science and Technology, Pohang 37673, Korea \\ ${ }^{3}$ Sustainable Agriculture Research Institute, Jeju National University, Jeju 63243, Korea \\ ${ }^{4}$ The Research Institute for Subtropical Agriculture and Biotechnology, Jeju National University, Jeju 63604, Korea
}

(Received on April 17, 2019; Revised on May 29, 2019; Accepted on June 19, 2019)

Melanose, caused by Diaporthe citri, is one of severe diseases in citrus, a major economic resource in Jeju island. To reduce the usage amount of organic synthetic fungicide, bio-sulfur was tested as an alternative chemical to control citrus melanose in the present study. Direct antifungal activity of bio-sulfur against $D$. citri was determined through in vitro experiment using artificial nutrient media. Disease severity of melanose on bio-sulfur pretreated citrus leaves was lower than that on untreated ones. To illustrate the mechanism of disease suppression by bio-sulfur, infection structures were observed with a fluorescent microscope and a scanning electron microscope. In fluorescent microscopic observation, most conidia rarely germinated. In addition, hyphal growth on leaves pretreated with biosulfur was inhibited compared to that on untreated ones. In scanning electron microscope images of biosulfur pretreated leaves, surfaces of most conidia were shrunk while hyphae were morphologically changed and frequently branched. Such microscopic observations were also found for leaves pretreated with a commercial fungicide Dithianon. These results suggest that bio-sulfur may be used to control citrus melanose as an

\footnotetext{
*Corresponding author.

Phone) +82-64-754-3319, FAX) +82-64-725-2351

E-mail) ycjeun@jejunu.ac.kr

ORCID

Yong Chull Jeun

https://orcid.org/0000-0002-9084-1393

(c) This is an Open Access article distributed under the terms of the Creative Commons Attribution Non-Commercial License (http:// creativecommons.org/licenses/by-nc/4.0) which permits unrestricted noncommercial use, distribution, and reproduction in any medium, provided the original work is properly cited.
}

Articles can be freely viewed online at www.ppjonline.org. environment friendly alternative to organic synthetic fungicides

Keywords : environment friendly, fluorescence microscope, infection behavior, scanning electron microscope

Handling Editor : Kim, Ki Woo

In Jeju island, cultivating area of mandarin was 21,241 ha, accounting for $33 \%$ of the whole farmland in this island in the year of 2015. Income from fruits as the major source of revenue in the island except for the tourist industry was about 600 billion Korean Won in the same year (Kang and Ko, 2018; Park et al., 2018). However, citrus melanose, caused by Diaporthe citri, has been one of serious diseases in many citrus orchards of Jeju island (Hyun et al., 2004). Increase of citrus cultivation has resulted in high density of trees in a farm, thus increasing the risk of melanose epidemic (Kwon et al., 2003). Melanose has decreased income by $8.5 \%$ due to reduced quality of fruits in commercial market (Hyun et al., 2013).

D. citri (asexual stage: Phomopsis citri) infects mostly leaves and fruits and produces inoculums in dead twigs as a saprophyte (Mondal et al., 2007). Two types of conidia have been reported. One is $\alpha$ type which has an oval shape without any color. The other was $\beta$ type which has a filamentous shape known without pathogenesis (Gopal et al., 2014). The optimal temperature of infection by $D$. citri is at 24 to $28^{\circ} \mathrm{C}$. Leaf wetness duration for infection is 8 to $16 \mathrm{~h}$ (Agostini et al., 2003).

To control melanose on citrus, fungicide Mancozeb has been usually used in most orchards (Yi et al., 2014). However, because total numbers of beneficial insects are decreased when Mancozeb is sprayed to citrus orchards and 
quality of citrus fruits is reduced due to fruits peel damaged by the fungicide (Miles et al., 2004; Smith and Papacek, 1991), some systemic fungicides such as strobilurins have been alternatively applied (Bushong and Timmer, 2000). Imprudent application of fungicides may cause high residue of fungicide in the crop product. Thus, new protection strategy which has less risk by misuse of systemic fungicide needs to be developed (Lee et al., 2014a).

Recently, the number of environment friendly farms is gradually increasing in Korea, including Jeju island where natural substance, organic resources, and microorganisms are used instead of systemic chemicals (Nam and Kim, 2002). Consequentially, agricultural products from environment friendly farms have reached $5.8 \%$ annually in the market of South Korea since 2018 (Jeong et al., 2018).

Indeed, usage of copper compound which is regarded as an alternative chemical has been increasingly used in citrus orchards due to increasing interest in environment friendly production in Korea including Jeju (Hyun et al., 2005). On the other hand, citrus melanose can be suppressed by some rhizobacterial strains such as Burkholderia gladioli, Pseudomonas fluorescens, Pseudomonas pudia, and Bacillus subtilis (Ko et al., 2012; Nnam et al., 2009), though its low efficacy and difficulty of formulation than a chemical fungicide (Han, 2012). The objective of the present study was to investigate whether bio-sulfur could suppress the severity of melanose in citrus plants in order to develop a new control strategy against citrus melanose. The antifungal effect of bio-sulfur against $D$. citri, was tested on artificial media and bio-test using citrus leaves. Furthermore, to illustrate the mechanism of disease suppression by biosulfur, infected citrus leaves were observed with a fluorescent microscope while fine structures of the fungus were observed with a scanning electron microscope.

\section{Material and Methods}

Plant material. Citrus trees (Clementine mandarin variety: Gungcheon) were grafted to a trifoliate orange tree and transplant to pots $(\varnothing=30 \mathrm{~cm})$ filled with commercial soils (Number-One, Hongseong, Korea) and 10\% perlite (Parat, Sam Son, Seoul, Korea). These citrus plants were placed in an incubation room maintained at $25^{\circ} \mathrm{C}$ with $90 \%$ humidity and $14 \mathrm{~h}$ of photosynthesis period. Each leaf of sprout at approximately 10 days after budding was cut with a sterilized razor blade and used for test.

Fungal isolate. Diaporthe citri causing melanose in citrus plants (Clementine mandarin variety: Gungcheon) was isolated in the laboratory as described previously (Ko et al., 2012). For sporulation, D. citri was grown on a potato dextrose agar (PDA; Becton, Dickinson and Company, Claix, France) medium under aerobic condition for 14 days according to published method (Ko et al., 2012). For inoculums, $10 \mathrm{ml}$ of distilled water was added onto PDA formed with pycnidia of fungus. Conidia were harvested using a loop and filtered with a double folded mira-cloth. The concentration of inoculum was adjusted to $1 \times 10^{5}$ conidia $/ \mathrm{ml}$ using a hemocytometer (Hausser Scientific Inc., Horsham, PA, USA).

In vitro evaluation. Bio-sulfur, consist of Thiobacillus sp. and element sulfur, was taken from Ecobio Holding Co. Ltd. (Incheon, Korea). To test the antifungal effect, biosulfur was added to PDA or potato dextrose broth (PDB; Becton, Dickinson and Company, Claix, France) to the concentration at $1,000 \mathrm{ppm}$. PDA was used to test antifungal effect of bio-sulfur. An agar block containing mycelium of $D$. citri was inoculated onto the center of PDA medium followed by incubation at $25^{\circ} \mathrm{C}$ for 7 days. Diameters of mycelia were measured with a ruler for untreated groups and groups treated with bio-sulfur or with Dithianon. For liquid medium, three mycelium blocks of $D$. citri were dropped into PDB followed by incubation at $25^{\circ} \mathrm{C}$ with shaking at $110 \mathrm{rpm}$ in a shaking incubator (HB-201SL, Hanbaek Scientific Co., Bucheon, Korea) for 7 days. Fresh weight of mycelia was measured with an electronic balance. Experiments were separately replicated three times and every experiment contained three media both PDA and PDB.

Bioassay evaluation. Leaves of citrus sprouts of 10 days old were inoculated with $D$. citri. These leaves were cut and laid in a Petri-dish $(\varnothing=90 \mathrm{~mm})$. The end of petiole was wrapped with cotton wool soaked with sterilized water. These citrus leaves were sprayed with sterilized water, bio-sulfur solution at $1,000 \mathrm{ppm}$, or Dithianon at $0.75 \mathrm{~g} /$ 1. After drying for $3 \mathrm{~h}$, the inoculum added with $0.01 \%$ Tween 20 (Yakuri Pure Chemicals Co., Kyoto, Japan) was dropped onto leaves 4 points every $10 \mu \mathrm{l}$ each followed by incubation in an incubator (DA MIL-2500, Dong-A, Siheung, Korea) at $25^{\circ} \mathrm{C}$ for 7 days. Diameters of infected sites showing symptoms of melanose were measured with a ruler. Experiments were separately replicated three times and every treatment contained three leaves.

Fluorescence microscopy. To determine the mechanism involved in disease suppression of bio-sulfur on citrus leaves, both treated with chemicals and untreated leaves were observed with a fluorescent microscope (BX60, 
Olympus, Tokyo, Japan) at 1, 3, and 5 days after inoculation. Ten microliters of inoculum suspension adjusted to 1 $\times 10^{5}$ conidia/ml was dropped on citrus leaves. Inoculated sites of samples were cut with a razor blade in size of 5 $\times 5 \mathrm{~mm}^{2}$ and fixed with $2 \%$ glutaraldehyde in phosphate buffer (pH 7.2) at $4^{\circ} \mathrm{C}$ for $2 \mathrm{~h}$. Fixed samples were washed with phosphate buffer three times (10 min each) and dyed with $2 \%$ diethanol (UVtex-2B, Fungiqual A, Muellheim, Germany) for $40 \mathrm{~m}$ at room temperature. These samples were washed phosphate buffer three times again $(10 \mathrm{~min}$ each) and mounted on glass slides with $70 \%$ glycerin (OCI Company Ltd., Seoul, Korea). Infected sites were observed with a fluorescent filter set (exciter filter, BP 400-440; interference beam splitter, FT 460; barrier filter, LP 470). The number of germinated conidia and hyphal length were determined for all treatment groups. Experiments were separately replicated three times using three samples for each treatment.

Scanning electron microscopy. Surfaces of inoculated citrus leaves both treated with chemicals and untreated were observed with a scanning electron microscope to see fine structures of $D$. citri. Inoculated parts of leaves were cut to sizes of $5 \times 5 \mathrm{~mm}^{2}$ and fixed with a $2 \%$ glutaraldehyde in cacodylic buffer ( $\mathrm{pH} 7.2)$ at $4^{\circ} \mathrm{C}$ for $2 \mathrm{~h}$. Samples were washed with cacodylic buffer three times (10 min each). Post fixation was carried out with $1 \%$ osmium tetroxide in cacodylic buffer at $4^{\circ} \mathrm{C}$ for $2 \mathrm{~h}$. These fixed samples were washed with distilled water two times for $10 \mathrm{~min}$ each. Dehydration was performed with $30 \%, 50 \%, 70 \%, 90 \%$, and $100 \%$ ethanol for $30 \mathrm{~min}$ each followed by treatment with $100 \%$ twice for $30 \mathrm{~min}$ each. Samples were dried with a critical point dryer (CPD 030, BAL-Tec, Los Angeles, CA, USA) and coated with platinum by sputter coater-platinum (Q150R Plus - Rotary Pumped Coater, Quorum Technologies Ltd., Sussex, UK) at $20 \mathrm{~mA}$ for $90 \mathrm{~s}$. Coated samples were observed with a field emission scanning electron microscope (FE-SEM Mira3, Tescan Ltd., Brno, Czech Republic).

Statistical analysis. Data of diameters of mycelia on the media for determining the antifungal effect of bio-sulfur, sizes of inoculated citrus leaves showing symptoms, the number of germinated conidia, and hyphal lengths on surfaces of citrus leaves were analyzed with Duncan's multiple range test using SAS program version 9.0 (SAS Institute Inc., Cary, NC, USA). Statistical significance was considered at $P<0.05$.

\section{Results and Discussion}

Antifungal activity of bio-sulfur on artificial media. At 7 days after inoculation, mycelial growth on PDA added with bio-sulfur was inhibited compared to that on untreated PDA (Fig. 1A and B). On PDA containing a commercial fungicide Dithianon, mycelia were rarely detected (Fig. 1C). Diameters of mycelia on PDA treated with bio-sulfur were decreased by $24 \%$ compared to those on untreated PDA, indicating that bio-sulfur had antifungal activity against $D$. citri. Dithianon also showed significant suppression effect on mycelia (Fig. 1D). The antifungal effect of bio-sulfur was apparent in PDB in which the contact extent of bio-sulfur was increased. At 7 days after inoculation, mycelial ball was smaller in the group treated with bio-sulfur than that of untreated group (Fig. 2A and B). Similarly, mycelial ball in the group treated with Dithianon was much smaller than that of the untreated group (Fig. 2C). Fresh weight of mycelia grown in bio-sulfur treated liquid media was also decreased to $65 \%$ compared to that of mycelia in the untreated group (Fig. 2D).

It has been reported that sulfur compound has direct antifungal effect on an artificial medium. Kim et al. (2018) have shown that paper disk containing loess-sulfur on PDA medium has antifungal activities against Colletotrichum
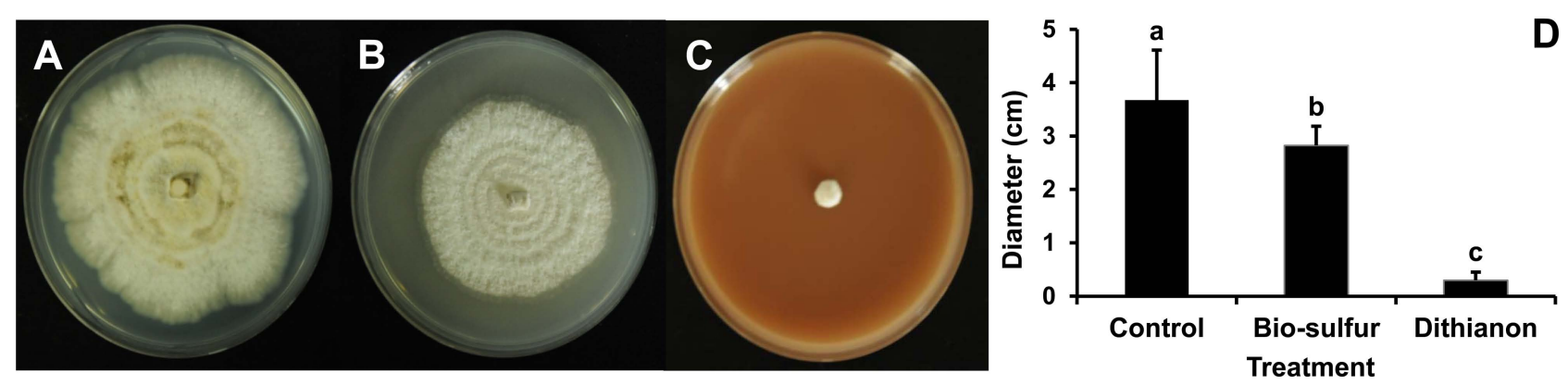

Fig. 1. Mycelium growth of Diaporthe citri on untreated potato dextrose agar (PDA) medium (A), PDA added with bio-sulfur (B), and PDA treated with a commercial fungicide Dithianon (C). The diameter of $D$. citri mycelia grown on PDA medium (D) is shown. Concentration of bio-sulfur suspension was $1,000 \mathrm{ppm}$. Photographs are taken at 7 days after fungal inoculation. 

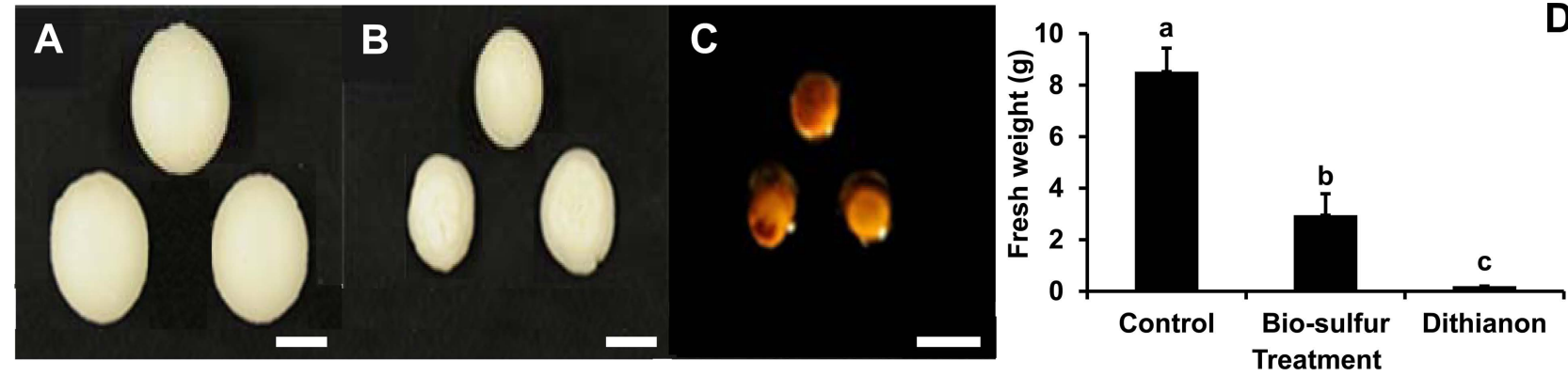

Fig. 2. Mycelium growth of Diaporthe citri on untreated potato dextrose broth (PDB) medium (A), PDB added with bio-sulfur (B), and PDB added with a commercial fungicide Dithianon (C). Fresh weight of mycelium of $D$. citri cultivated in untreated PDB, PDB added with bio-sulfur, or PDB added with Dithianon (D) is shown. Concentration of bio-sulfur suspension was $1,000 \mathrm{ppm}$. Scale bars $=1 \mathrm{~cm}$. Photographs are taken at 7 days after fungal inoculation.

gloeosporioides known to cause anthracnose in jujube. Also, inorganic sulfur compound on PDA media added with an inorganic sulfur has a distinctive growth inhibition effect on Cylindrocarpon destructans and Fusarium solani known to cause root rot in ginseng plant (Lee et al., 2014b). Furthermore, mycelium growth of Fusarium oxysporum causing vascular wilts in various plants is decreased on PDA medium added with sulfur nanoparticles (Choudhury et al., 2011). In the present study, both diameter of $D$. citri on bio-sulfur added PDA medium and weight of mycelia in PDB medium containing bio-sulfur were decreased clearly compared to those of untreated group (Figs. 1 and 2). In order to evaluate the antifungal activity of bio-sulfur comparing to the commercial fungicide Dithianon in the farm, concentration of the fungicide applying in the field was applied in this study. These results revealed a direct antifungal effect of bio-sulfur against $D$. citri on artificial media.

Disease suppression of bio-sulfur against melanose on citrus leaves. Disease severity on bio-sulfur pretreated leaves was highly inhibited compared to that of untreated one (Fig. 3A and B), indicating that bio-sulfur had disease suppression capacity. However, the protection rate by biosulfur was not as high as Dithianon. After pretreatment with Dithianon, disease symptoms were hardly observed (Fig. 3C). Average sizes of leaves showing disease symptoms in both treatment groups (bio-sulfur or Dithianon) were significantly reduced compared to those of untreated group (Fig. 3D).

It has been known that sulfur contains substance that could suppress disease severity of some crop plants. It has been reported that disease severity of powdery mildew is decreased by about $90 \%$ in tomato plants treated with loess-sulfur mixture (Shim et al., 2014). Ginseng anthracnose caused by Colletotrichum gloeosporioides is also suppressed by treatment with lime sulfur diluted 400 times (Lim et al., 2015). Sulfur containing salts can also inhibit postharvest diseases such as carrot cavity spot caused by Pythium sulcatum and potato dry rot caused by Fusarium sambucinum (Kolaei et al., 2012). Likewise, disease sever-
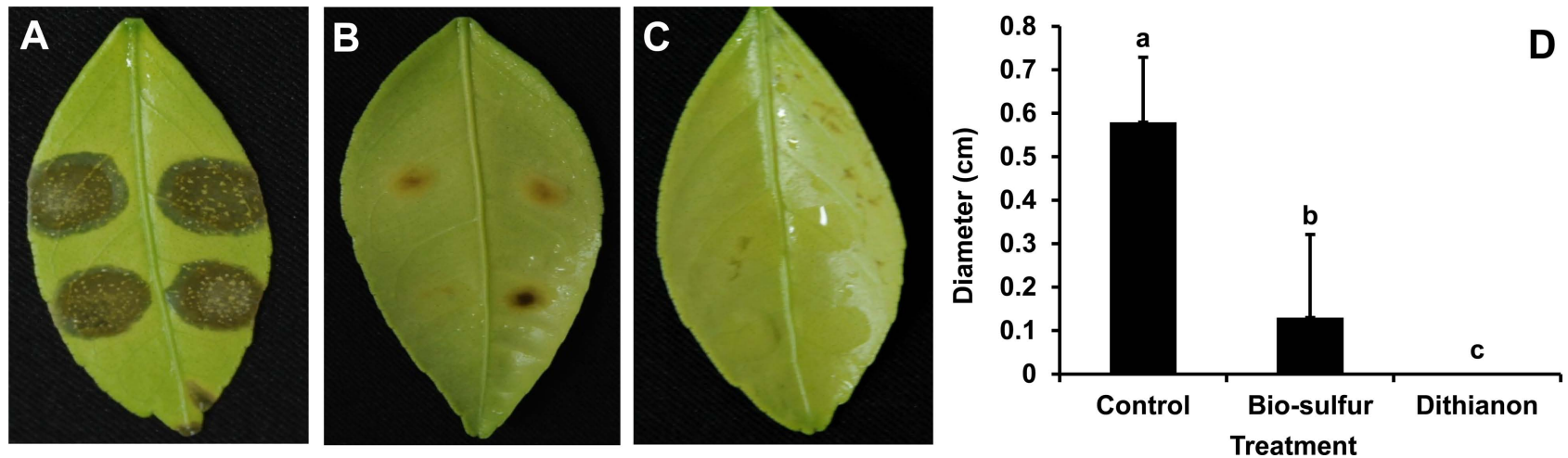

Fig. 3. Disease severity on citrus leaves untreated (A), pretreated with bio-sulfur (B), or pretreated with a commercial fungicide Dithianon (C). Diameters of lesions on citrus leaves untreated, added with bio-sulfur, or added with Dithianon at 7 days after inoculation with $D$. citri (D) are shown. Concentrations of fungal pathogen, bio-sulfur, and Dithianon suspension were $1 \times 10^{5} \mathrm{conidia} / \mathrm{ml}, 1,000 \mathrm{ppm}$, and 0.75 $\mathrm{g} / \mathrm{l}$, respectively. 


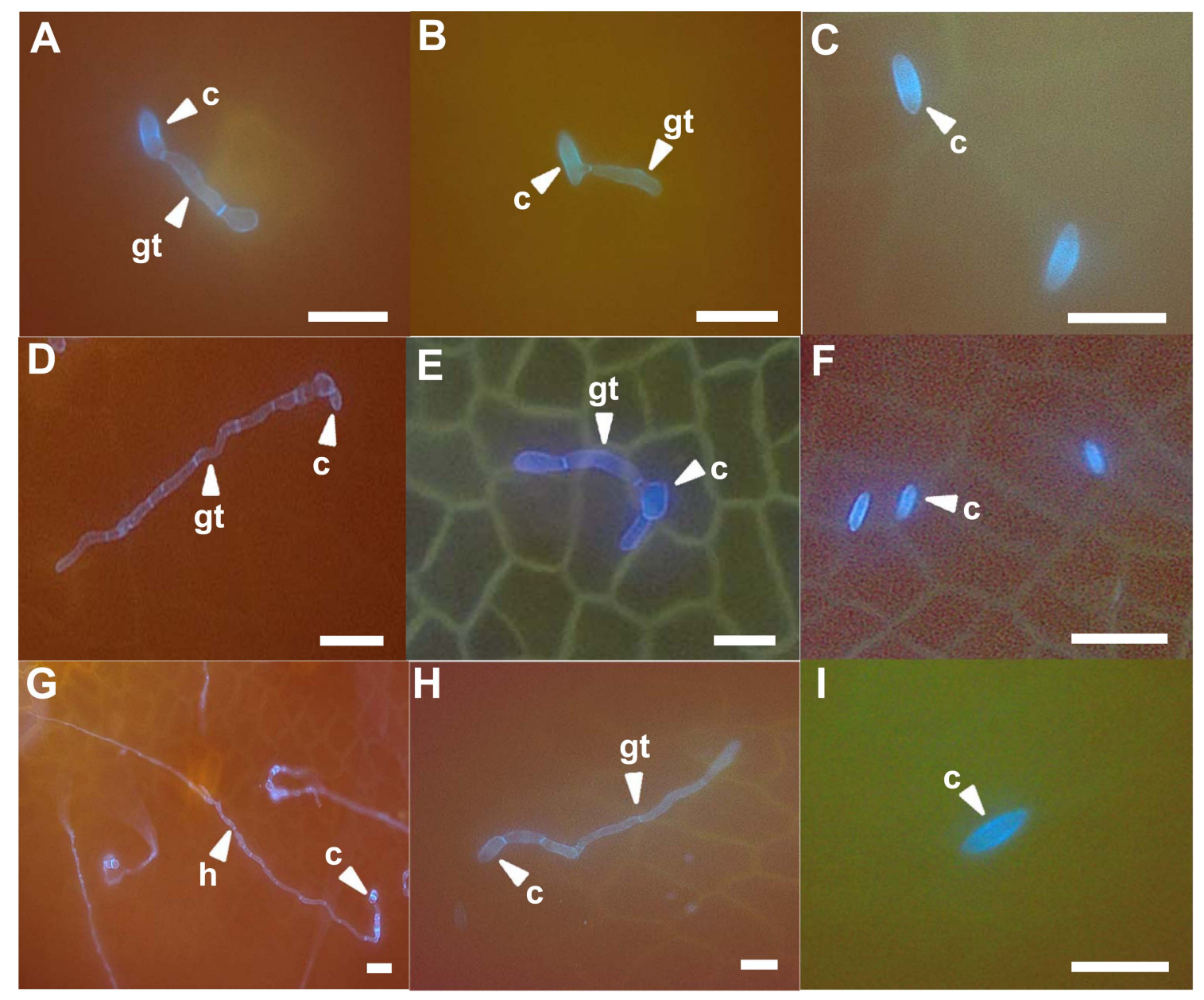

Fig. 4. Fluorescence microscopical observations of infection structures at 1, 3, and 5 days after inoculation on leaves of citrus untreated (left column up to down A, D, and G), pretreated with bio-sulfur (middle column up to down B, E, and H), or pretreated with a commercial fungicide Dithianon (right column up to down C, F, and I). The suspension of bio-sulfur was diluted 500 times. Concentrations of fungal pathogen, bio-sulfur, and Dithianon suspension were $1 \times 10^{5}$ conidia $/ \mathrm{ml}, 1,000 \mathrm{ppm}$, and $0.75 \mathrm{~g} / 1$, respectively. Scale bars $=20 \mu \mathrm{m}$. c, conidium; h, hyphae; gt, gum tube.

ity caused by $D$. citri on citrus leaves was decreased by pretreatment with bio-sulfur in the present study (Fig. 3), suggesting that bio-sulfur could be a candidate substance as a new fungicide.

Fluorescent microscopic observations of surfaces of citrus leaves. To compare the infection behavior of $D$. citri, citrus leaves pretreated with bio-sulfur or Dithianon were observed with a fluorescent microscope. Most conidia were germinated at 1 day after inoculation. They grew fast to form mycelium at 5 days after inoculation on untreated citrus leaves (Fig. 4A, D, and G). However, germination rate of conidia on bio-sulfur pretreated leaves were apparently decreased (Fig. 5A). In addition, most of hyphal growths were limited compared to untreated group (Figs. 4B, E, $\mathrm{H}$, and $5 \mathrm{~B}$ ). These results indicate that conidial germina- tion and hyphal growth could be inhibited by bio-sulfur. Most conidia could not germinate on leaves pretreated with Dithianon until 3 days after inoculation (Figs. 4C, F, and $5 A)$. Lengths of hyphae in the group treated with Dithianon were smaller than those in the group treated with bio-sulfur (Fig. 5B), explaining why Dithianon had stronger inhibition effect on melanose disease severity (Fig. 3).

Inhibition of sulfur on spore germination has been reported in many plants. For example, conidial germination rate of Stemphylium botryosum causing garlic leaf blight is decreased more than $90 \%$ on garlic leaves treated with sulfur compound (Ryu et al., 2015). Less conidial germination rate of Erysiphe cichoracearum causing powdery mildew on okra treated with sulfur fungicides such as nanosulphur, Canadian nanosulphur, Merck Sulphur, and sulphur 80 WP has also been reported (Gogoi et al., 2013). Conidial ger- 

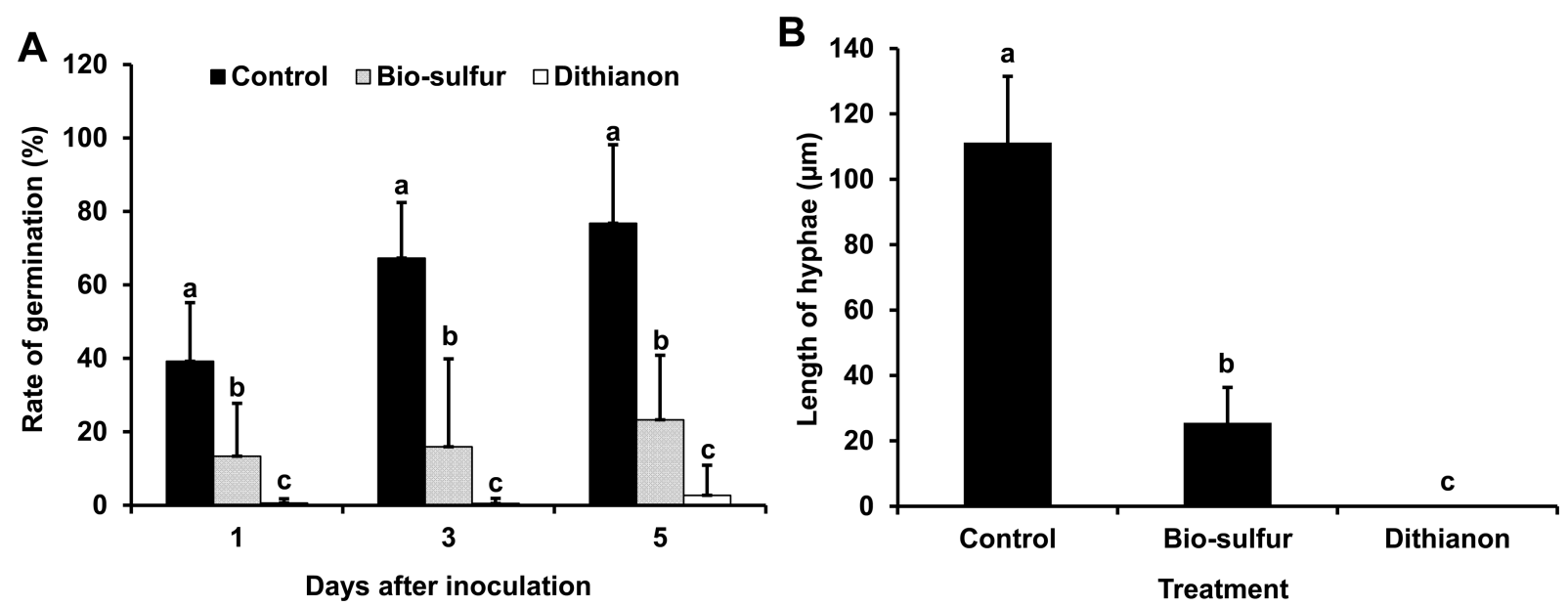

Fig. 5. Germination rate of Diaporthe citri on citrus leaves untreated, pretreated with bio-sulfur, or pretreated with a commercial fungicide Dithianon (A) and length of hyphae at 3 days after inoculation (B). The suspension of bio-sulfur was diluted 500 times. Concentrations of fungal pathogen, bio-sulfur, and Dithianon suspension were $1 \times 10^{5}$ conidia/ml, $1,000 \mathrm{ppm}$, and $0.75 \mathrm{~g} / \mathrm{l}$, respectively.

mination rate of Botrytis cinerea is also inhibited $99 \%$ by buffered grape juice containing sulfur dioxide at $2.8 \mu \mathrm{g} / \mathrm{ml}$ (Smilanick et al., 1990).

It is well-known that inhibition of hyphal growth is a major cause of disease suppression on many crop plants. Mycelium growth of gray mold caused by $B$. cinerea on grapefruits is inhibited by treatment with sulfur dioxide fumigation, resulting in decreased severity of gray mold (Gabler et al., 2010). Also, inhibition of mycelium growth by sulfur can control disease caused by Acremonium acutatum or Trichothecium roseum on grapes (Oh et al., 2014). In case of peach fruit fumigated with sodium hydrosulfide, mycelium development of Monilinia fructicola causing brown rot is reduced, resulting in less disease incidence (Wu

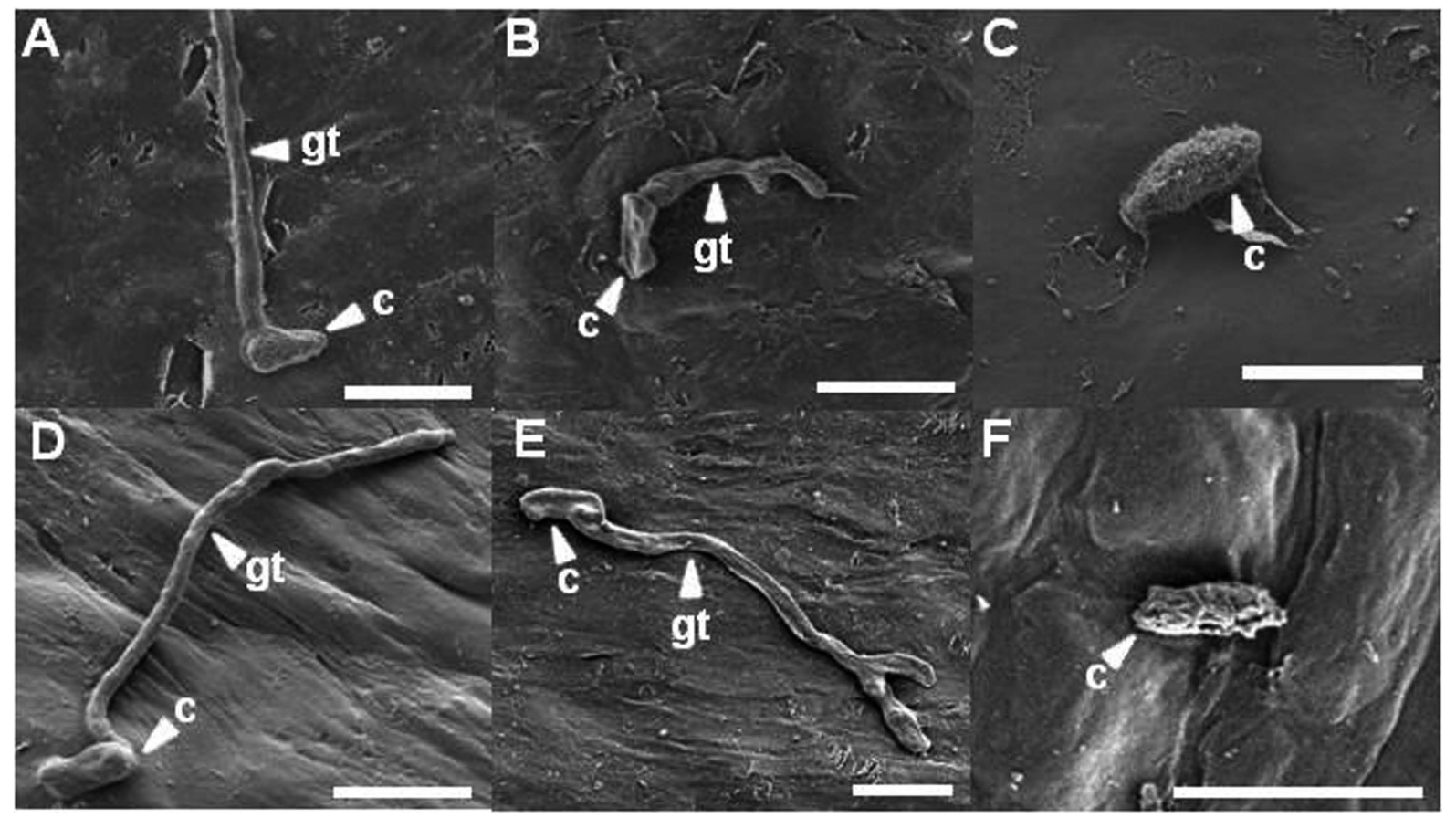

Fig. 6. Scanning electron microscopical observations of infection structures at 1 and 3 days after fungal inoculation on citrus leaves untreated (left up to down A and D), pretreated with bio-sulfur (middle up to down B and E), or pretreated with a commercial fungicide Dithianon (right up to down $\mathrm{C}$ and F). The suspension of bio-sulfur was diluted 500 times. Concentrations of fungal pathogen, bio-sulfur, and Dithianon suspension were $1 \times 10^{5}$ conidia $/ \mathrm{ml}, 1,000 \mathrm{ppm}$, and $0.75 \mathrm{~g} / \mathrm{l}$, respectively. Scale bars $=10 \mu \mathrm{m}$. c, conidium; gt, gum tube. 
et al., 2018). These observations imply that low germination rate of conidia and inhibition of hyphal growth by biosulfur might be major factors decreasing melanose severity on citrus leaves.

Ultra-structural observations of $D$. citri on citrus leaves using scanning electron microscope. Citrus leaves were observed with a scanning electron microscope to reveal the ultra-structure of $D$. citri. At 1 and 3 days after inoculation, morphologies of most conidia and hyphae were intact on untreated citrus leaves (Fig. 6A and D). At 5 days after inoculation, a lot of hyphae were entangled. Tangles of hyphae showed a smooth surface on untreated citrus leaves (data not shown). However, on citrus leaves pretreated with bio-sulfur, most conidia were not germinated. Some germinated conidia were shrunk at 1 day after inoculation (Fig. 6B). At 3 days after inoculation, some conidia were flat and tidy compared to those of untreated one. Also, some hyphae were morphologically deformed and branched (Fig. 6E). Two days later, morphologically changed conidia and branched hyphae were frequently observed (data not shown), indicating that conidia and hyphae of D. citri were directly affected by bio-sulfur. More than twofold numbers was counted in the hyphal branch on the observed scanning electron microscopy images pretreated with bio-sulfur compared with those of untreated one (data not shown). On Dithianon pretreated leaves, conidia were rarely found at all time of observations (Fig. 6C). Most surfaces of conidia were puckered and reduced in size at 3 days after inoculation (Fig. 6F). These phases were also shown similarly on citrus leaves at 5 days after inoculation, showing shrunk and roughed conidia (data not shown).

Some reports have revealed that fungal structures are modified by treatment with sulfur compounds. For examples, hyphae of Penicillium italicum on mandarin fruit fumigated with hydrogen sulfide are modified, leading to decrease of citrus blue mold (Fu et al., 2014). Also, modification of conidia and hyphae of Aspergillus niger by spray with sulfur might lead to inhibition of powdery mildew on mango (Reuveni et al., 2018). Morphological changes or forming branch of filamentary fungus indicate harmful environment such as exposure to chemicals or fungicide. Therefore, bio-sulfur may play a role as a fungicide to control melanose.

In conclusion, bio-sulfur treatment can significantly decrease conidia germination and hyphal growth of $D$. citri. When fungus had contact with bio-sulfur, modification of conidia and hyphae was detected morphologically. These results suggest that bio-sulfur can be used to control melanose in eco-friendly citrus farms where the use of chemi- cals is limited. However, in order to use bio-sulfur in the farm practically it should be prior to test either its toxicity in agricultural environment or its influence by chemical residue in human health.

\section{Acknowledgments}

This work was supported by Korea Institute of Planning and Evaluation for Technology in Food, Agriculture, Forestry (IPET) through Advanced Production Technology Development Program, funded by Ministry of Agriculture, Food and Rural Affairs (MAFRA) (117015-02).

\section{References}

Agostini, J. P., Bushong, P. M., Bhatia, A. and Timmer, L. W. 2003. Influence of environmental factors on severity of citrus scab and melanose. Plant Dis. 87:1102-1106.

Bushong, P. M. and Timmer, L. W. 2000. Evaluation of postinfection control of citrus scab and melanose with benomyl, fenbuconazole, and azoxystrobin. Plant Dis. 84:1246-1249.

Choudhury, S. R., Ghosh, M., Mandal, A., Chakravorty, D., Pal, M., Pradhan, S. and Goswami, A. 2011. Surface-modified sulfur nanoparticles: an effective antifungal agent against Aspergillus niger and Fusarium oxysporum. Appl. Microbiol. Biotechnol. 90:733-743.

Fu, L.-H., Hu, K.-D., Hu, L.-Y., Li, Y.-H., Hu, L.-B., Yan, H., Liu, Y.-S. and Zhang, H. 2014. An antifungal role of hydrogen sulfide on the postharvest pathogens Aspergillus niger and Penicillium italicum. PLoS ONE 9:e104206.

Gabler, F. M., Mercier, J., Jiménez, J. I. and Smilanick, J. L. 2010. Integration of continuous biofumigation with Muscodor albus with pre-cooling fumigation with ozone or sulfur dioxide to control postharvest gray mold of table grapes. Postharvest Biol. Technol. 55:78-84.

Gogoi, R., Singh, P. K., Kumar, R., Nair, K. K., Alam, I., Srivastava, C., Yadav, S., Gopal, M., Choudhury, S. R. and Goswami, A. 2013. Suitability of nano-sulphur for biorational management of powdery mildew of okra (Abelmoschus esculentus Moench) caused by Erysiphe cichoracearum. J. Plant Pathol. Microbiol. 4:171.

Gopal, K., Lakshmi, L. M., Sarada, G., Nagalakshmi, T., Sankar, T. G., Gopi, V. and Ramana, K. T. V. 2014. Citrus melanose (Diaporthe citri Wolf): a review. Int. J. Curr. Microbiol. Appl. Sci. 3:113-124.

Han, S. G. 2012. The productivity and the evaluation of environmental impact with characteristics environmentally friendly agricultural materials. Ph.D. thesis. Chungnam National University, Daejeon, Korea. 104 pp.

Hyun, J.-W., Kim, D.-H., Kim, K.-S., Lee, S.-C., Ko, S.-W. and Lim, H.-C. 2004. Diseases and the symptoms recently occurred on 'Shiranuhi' citrus cultivar in Jeju island. Res. Plant Dis. 10:94-99 (in Korean). 
Hyun, J.-W., Ko, S.-W., Kim, D.-H., Han, S.-G., Kim, K.-S., Kwon, H.-M. and Lim, H.-C. 2005. Effective usage of copper fungicides for environment-friendly control of citrus diseases. Res. Plant Dis. 11:115-121.

Hyun, J.-W., Yi, P.-H., Hwang, R.-Y. and Moon, K.-H. 2013. Aspect of incidence of the major citrus diseases recently. Res. Plant Dis. 19:102-107 (in Korean).

Jeong, H. K., Sung, J. H. and Lee, H. J. 2018. Current issue and policy on market condition of internal and external environment-friendly agricultural products in 2018. Vol. 169. Korea Rural Economic Institute, Naju, Korea. 11 pp.

Kang, S.-K. and Ko, B.-H. 2018. A causality analysis of the tangerine market by distribution channel. J. Korea Acad. Ind. Coop. Soc. 19:376-381.

Kim, S. J., Kim, E. S., Kim, S. H. and Yun, H. K. 2018. Inhibitory effects of environment-friendly materials and defense response signaling chemicals against anthracnose occurrence in Jujube (Zizyphus jujuba Miller). Korean J. Agric. Sci. 45:365378.

Ko, Y. J., Kang, S. Y. and Jeun, Y. C. 2012. Suppression of citrus melanose on the leaves treated with rhizobacterial strains after inoculation with Diaporthe citri. Res. Plant Dis. 18:331337 (in Korean).

Kolaei, E. A., Tweddell, R. J. and Avis, T. J. 2012. Antifungal activity of sulfur-containing salts against the development of carrot cavity spot and potato dry rot. Postharvest Biol. Technol. 63:55-59.

Kwon, H.-M., Nam, K.-W., Kim, K.-S., Kim, D.-H., Lee, S.-C. and Hyeon, J.-W. 2003. Characterization of the causal fungus of citrus melanose, Diaphorthe citri isolated from blighted twigs of citrus in Jeju. Res. Plant Dis. 9:153-158 (in Korean).

Lee, J. B., Hong, S.-M., Kwon, H.-Y., You, A.-S., Hong, S.-S. and Ihm, Y. 2014a. Safety evaluation of pesticide residue in five fruits by dietary risk index. Korean J. Pestic. Sci. 18:336-341.

Lee, S. W., Lee, S. H., Park, K. H., Jang, I. B., Jin, M. L. and Kim, K. H. 2014b. Effect of irrigation of sulfur solution before sowing on growth and root rot disease of seedling in ginseng nursery. Korean J. Med. Crop Sci. 22:391-397.

Lim, J.-S., Mo, H.-S., Lee, E.-H., Park, K.-C. and Chung, C.-M. 2015. Suppressive effects of sulfur-containing compounds on ginseng anthracnose (Colletotrichum gloeosporioides) and proper application concentration. Korean J. Environ. Agric. 34:46-51.

Miles, A. K., Willingham, S. L. and Cooke, A. W. 2004. Field evaluation of strobilurins and a plant activator for the control of citrus black spot. Australas. Plant Pathol. 33:371-378.

Mondal, S. N., Vicent, A., Reis, R. F. and Timmer, L. W. 2007.
Saprophytic colonization of citrus twigs by Diaporthe citri and factors affecting pycnidial production and conidial survival. Plant Dis. 91:387-392.

Nam, K.-W. and Kim, S.-H. 2002. Effect on fruit quality and tree's main disease control by agro-chemical alternatives. Korean J. Org. Agric. 10:67-77.

Nnam, M.-H., Shin, J.-H., Choi, J.-P., Hong, S.-I., Kim, Y.-G. and Kim, H.-T. 2009. Identification of Rhizo-bacterium inhibiting Diaporthe citri causing citrus melanose. Korean J. Pestic. Sci. 13:332-335.

Oh, S.-Y., Nam, K.-W. and Yoon, D.-H. 2014. Effect of environmental-friendly control for white stain symptom on grape. Korean J. Environ. Agric. 33:184-188.

Park, J. S., Seo, Y. A., Kin, K. R. and Ha, J.-C. 2018. Evaluating the prediction models of leaf wetness duration for citrus orchards in Jeju, South Korea. Korean J. Agric. For. Meterol. 20:262-276.

Reuveni, M., Gur, L. and Farber, A. 2018. Development of improved disease management for powdery mildew on mango trees in Israel. Crop Prot. 110:221-228.

Ryu, Y.-H., Huh, C.-S., Kim, D.-G., Yeon, I.-K., Jo, W.-S. and Ryu, J.-A. 2015. Controlling effect of some environmentally friendly agents on garlic leaf blight in garlic. Korean J. Org. Agric. 23:347-357.

Shim, C.-K., Kim, M.-J., Kim, Y.-K., Hong, S.-J. and Kim, S.-C. 2014. Reducing phytotoxic by adjusted $\mathrm{pH}$ and control effect of loess-sulfur complex as organic farming material against powdery mildew in tomato. Korean J. Pestic. Sci. 18:376382.

Smilanick, J. L., Hartsell, P. I., Henson, D., Fouse, D. C., Assemi, M. and Harris, C. M. 1990. Inhibitory activity of sulfur dioxide on the germination of spores of Botrytis cinerea. Phytopathology 80:217-220.

Smith, D. and Papacek, D. F. 1991. Studies of the predatory mite Amblyseius victoriensis (Acarina: Phytoseiidae) in citrus orchards in south-east Queensland: control of Tegolophus australis and Phyllocoptruta oleivora (Acarina: Eriophyidae), effect of pesticides, alternative host plants and augmentative release. Exp. Appl. Acarol. 12:195-217.

Wu, W., Zhang, C., Chen, L., Li, G., Wang, Q. and Shi, J. 2018. Inhibition of hydrogen sulfide and hypotaurine on Monilinia fructicola disease in peach fruit. Acta Hortic. 1194:257-266.

Yi, P.-H., Hyun, J.-W., Hwang, R.-Y. and Kim, K.-S. 2014. Improvement of control efficacy of mancozeb wettable powder against citrus melanose by mixing with paraffin oil. Res. Plant Dis. 20:196-200 (in Korean). 